BMJ Open Diabetes Research \& Care

\section{Sex differences in cardiometabolic risk factors, pharmacological treatment and risk factor control in type 2 diabetes: findings from the Dutch Diabetes Pearl cohort}

To cite: de Jong M, Oskam MJ, Sep SJS, et al. Sex differences in cardiometabolic risk factors, pharmacological treatment and risk factor control in type 2 diabetes: findings from the Dutch Diabetes Pearl cohort. BMJ Open Diab Res Care 2020;8:e001365. doi:10.1136/ bmjdrc-2020-001365

- Supplemental material is published online only. To view please visit the journal online (http://dx.doi.org/10.1136/ bmjdrc-2020-001365).

MdJ and MJO contributed equally.

Received 13 March 2020

Revised 21 July 2020

Accepted 25 July 2020

Check for updates

(C) Author(s) (or their employer(s)) 2020. Re-use permitted under CC BY. Published by BMJ.

For numbered affiliations see end of article.

Correspondence to Bruce H R Wolffenbuttel; bwo@umcg.nl

\section{ABSTRACT}

Introduction Sex differences in cardiometabolic risk factors and their management in type 2 diabetes (T2D) have not been fully identified. Therefore, we aimed to examine differences in cardiometabolic risk factor levels, pharmacological treatment and achievement of risk factor control between women and men with T2D.

Research design and methods Cross-sectional data from the Dutch Diabetes Pearl cohort were used $(n=6637$, $40 \%$ women). Linear and Poisson regression analyses were used to examine sex differences in cardiometabolic risk factor levels, treatment, and control.

Results Compared with men, women had a significantly higher body mass index (BMI) (mean difference $1.79 \mathrm{~kg} /$ $\mathrm{m}^{2}$ (95\% $\mathrm{Cl} 1.49$ to 2.08)), while no differences were found in hemoglobin $\mathrm{A}_{4 \mathrm{c}}\left(\mathrm{HbA}_{1 \mathrm{c}}\right)$ and systolic blood pressure (SBP). Women had lower diastolic blood pressure $(-1.94 \mathrm{~mm} \mathrm{Hg}(95 \%$ $\mathrm{Cl}-2.44$ to -1.43$))$, higher total cholesterol (TC) $(0.44 \mathrm{mmol} / \mathrm{L}$ $(95 \% \mathrm{Cl} 0.38$ to 0.51$))$, low-density lipoprotein cholesterol (LDL-C) $(0.26 \mathrm{mmol} / \mathrm{L}(95 \% \mathrm{Cl} 0.22$ to 0.31$))$, and high-density lipoprotein cholesterol (HDL-c) sex-standardized $(0.02 \mathrm{mmol} / \mathrm{L}$ (95\% $\mathrm{Cl} 0.00$ to 0.04$))$, and lower TC:HDL ratio $(-0.29(95 \% \mathrm{Cl}$ -0.36 to -0.23$)$ ) and triglycerides (geometric mean ratio 0.91 $(95 \% \mathrm{Cl} 0.85$ to 0.98$)$ ). Women had a $16 \%$ higher probability of being treated with antihypertensive medication in the presence of high cardiovascular disease (CVD) risk and elevated SBP than men (relative risk 0.84 (95\% $\mathrm{Cl} 0.73$ to 0.98$)$ ), whereas no sex differences were found for glucose-lowering medication and lipid-modifying medication. Among those treated, women were less likely to achieve treatment targets of $\mathrm{HbA}_{1 \mathrm{c}}(0.92$ (95\% Cl 0.87 to 0.98$)$ ) and LDL-C (0.89 (95\% Cl 0.85 to 0.92)) than men, while no differences for SBP were found. Conclusions In this Dutch T2D population, women had a slightly different cardiometabolic risk profile compared with men and a substantially higher BMI. Women had a higher probability of being treated with antihypertensive medication in the presence of high CVD risk and elevated SBP than men, and were less likely than men to achieve treatment targets for $\mathrm{HbA}_{1 \mathrm{c}}$ and $\mathrm{LDL}$ levels.
Significance of this study

What is already known about this subject?

- There is a growing body of evidence that type 2 diabetes (T2D) is a stronger risk factor for cardiovascular complications in women than in men.

- We aimed to evaluate sex differences in the levels of cardiometabolic risk factors, pharmacological treatment and achievement of treatment targets for hemoglobin $\mathrm{A}_{1}\left(\mathrm{HbA}_{t}\right)$, systolic blood pressure (SBP) and low-density lipoprotein cholesterol (LDL-c), in a large, well-phenotyped cohort of Dutch individuals with T2D.

What are the new findings?

- Women, especially those with lower and middle educational levels, had a substantially higher body mass index than men, while other cardiometabolic risk factors were highly comparable.

Women were more likely to receive antihypertensive medication in the presence of high cardiovascular disease risk and increased SBP, while no differences were found for glucose-lowering or lipid-lowering medication.

\section{INTRODUCTION}

Sexual heterogeneity has emerged as a major topic in several medical areas, including metabolic disorders such as type 2 diabetes (T2D). ${ }^{1}$ A growing body of evidence shows that the relative risk (RR) of cardiovascular complications associated with T2D is different for women and men. In fact, T2D may attenuate the protective effect that female sex usually confers on the risk of cardiovascular disease (CVD).$^{2-5}$ Meta-analyses have shown that the RR of coronary heart disease is up to 


\section{Significance of this study}

How might these results change the focus of research or clinical practice?

Although sex differences in cardiovascular risk management among individuals with $\mathrm{T} 2 \mathrm{D}$ are relatively small in the Netherlands, body mass index was almost two-point higher in women than in men, and more effective weight loss interventions are clearly needed.

- Furthermore, women had greater difficulty in attaining optimal $\mathrm{HbA}_{1 \mathrm{c}}$ and LDL-c treatment targets despite pharmacological treatment than men, and therefore future research should evaluate sex differences in adherence, drug type or dosage, and the underlying reasons for these differences in men and women with T2D.

$50 \%$ higher in women with diabetes, compared with their male counterparts. ${ }^{6-8}$ For stroke, this RR is $27 \%$ greater in women with diabetes than in men. ${ }^{9}$ The reasons for these sex differences are likely multifactorial, for example physiological differences between women and men, including the impact of sex hormones, ${ }^{10-12}$ femalespecific factors such as age of menarche, menopause, and childbearing history, oral contraception, and hormone replacement therapy ${ }^{13-15}$ and a more adverse cardiometabolic risk profile among women than men with T2D. ${ }^{1617}$ In addition, healthcare provision for the prevention and delay of cardiovascular complications between men and women with diabetes may differ. ${ }^{13} 15$ 17-21

Understanding of the sex differences in major modifiable risk factors with respect to their quantity, treatment and control in specific healthcare settings may help healthcare professionals to reduce these differences. In order to evaluate sex differences in the levels of cardiometabolic risk factors, pharmacological treatment and achievement of treatment targets for hemoglobin $\mathrm{A}_{1 \mathrm{c}}\left(\mathrm{HbA}_{1 \mathrm{c}}\right)$, systolic blood pressure and low-density lipoprotein cholesterol (LDL-c), in a large, well-phenotyped cohort of Dutch individuals with T2D, we used data from the Diabetes Pearl cohort. The Diabetes Pearl is a large Dutch cohort involving all eight academic medical centers in the Netherlands, covering different geographical areas, and has collected data from over 6500 individuals with T2D who are being treated in primary, secondary and tertiary care. ${ }^{22}$

\section{RESEARCH DESIGN AND METHODS Study population}

Cross-sectional data from the Diabetes Pearl, an observational cohort study, involving all eight Dutch academic medical centers covering different geographical areas in the Netherlands, and covering individuals treated in primary, secondary and tertiary care, were used, as described in detail elsewhere. ${ }^{22}$ In short, individuals previously diagnosed with T2D who received secondary or tertiary medical care in one of the six academic medical centers in Amsterdam, Utrecht, Nijmegen, Rotterdam, Leiden or Groningen, primary medical care in the area of Hoorn, or who received primary, secondary or tertiary care in the region of Maastricht were eligible for participation. ${ }^{22}$ In 2018, an estimated 1.2 million ( $47 \%$ women) individuals in the Netherlands had diabetes, with majority suffering from T2D $(91 \%) .{ }^{23}$ Individuals with T2D are predominantly being treated in primary care (up to $85 \%$ ). In the occurrence of complications of whenever glycemic control is not achieved by primary care, the patient will be referred to secondary care (ie, internal medicine, cardiology, ophthalmology, endocrinology). Only when high specialist care is needed, in complex cases, the patient is referred to tertiary care. ${ }^{22}$ Data were collected over a 6-year period (2009-2015) and included information on demographics, physical measurements, laboratory tests and questionnaires. Individuals were not included in the cohort if their ability to understand and write in Dutch language was too limited to provide written informed consent. ${ }^{22} \mathrm{~A}$ total of 6666 individuals diagnosed with T2D were included in the Diabetes Pearl. After excluding participants of whom sex was not known (missing), 6637 remained for analyses.

\section{Measurements}

Data on educational level (as a proxy for socioeconomic status), smoking behavior, alcohol consumption, history of diabetes, stroke, and CVD were obtained at baseline, using a self-report questionnaire. Information on sex and date of birth was obtained using the hospital information systems at all recruitment centers. Weight and height were measured barefoot and wearing light clothing using a clinical stadiometer and scale. Blood pressure was determined three times on the right arm after a $10 \mathrm{~min}$ rest period, using a non-invasive blood pressure monitor (Omron $7051 \mathrm{~T}$ in seven centers and Colin Press BP $8800 \mathrm{p}$ in one center). Final blood pressure was calculated as the mean of the last two measurements. Fasting venous blood plasma was used to determine total cholesterol (TC), high-density lipoprotein cholesterol (HDLc), and triglycerides. A fasting whole blood sample was used to determine $\mathrm{HbA}_{1 \mathrm{c}}$ level. All the laboratories were certified and located on-site in the eight clinics. ${ }^{22}$

\section{Cardiometabolic profile}

The following cardiometabolic risk factors were analyzed: systolic blood pressure (SBP), diastolic blood pressure (DBP), triglycerides, TC, HDL-c, LDL-c, TC:HDL ratio, body mass index (BMI), and $\mathrm{HbA}_{1 c}$. Triglyceride levels were $\log$-transformed due to non-normality and backtransformed to a geometric mean ratio. For HDL-c, specific cut-offs apply for women and men. Therefore, sex-standardized variables for HDL-c were used in the analyses of mean differences (MD) between women and men. Sex-standardized HDL-c was calculated as the observed value minus $1.2 \mathrm{mmol} / \mathrm{L}$ for women and the observed value minus $1.0 \mathrm{mmol} / \mathrm{L}$ for men. 
Table 1 Study population characteristics stratified by sex

$\begin{array}{ll}\text { Men, } & \text { Women, } \\ n=3969(60 \%) & n=2668(40 \%)\end{array}$

\begin{tabular}{lll}
\hline Age, years & $62.7 \pm 9.6$ & $61.8 \pm 11.1$ \\
$\begin{array}{l}\text { Diabetes duration, } \\
\text { years }\end{array}$ & $9.1(4.3-15.1)$ & $9.0(4.4-15.1)$
\end{tabular}

Educational level ${ }^{*}$$$
\text { Low }
$$$$
1169 \text { (32) }
$$

Moderate

$1558(42)$

$1066(43)$

High

$968(26)$

1065 (43)

$335(14)$

Smoking status

Never

$935(27)$

$1111(46)$

Former

1904 (54)

925 (39)

Current

$690(20)$

$360(15)$

Alcohol use†

$$
\text { No }
$$

1241 (33)

$1484(60)$

Low

1987 (53)

$738(30)$

High

Prior CVD

516 (14)

$248(10)$

1420 (40)

$673(30)$

10-year CVD risk

\begin{tabular}{lll} 
Low risk & $108(3)$ & $288(12)$ \\
\hline Intermediate risk & $187(5)$ & $336(14)$ \\
\hline $\begin{array}{l}\text { High risk } \\
\text { Healthcare setting }\end{array}$ & $3271(92)$ & $1759(74)$ \\
$\begin{array}{l}\text { Primary care } \\
\begin{array}{l}\text { Secondary/tertiary } \\
\text { care }\end{array}\end{array}$ & $1701(43)$ & $1489(56)$ \\
\end{tabular}

Cardiometabolic factors

\begin{tabular}{|c|c|c|}
\hline $\begin{array}{l}\text { Systolic blood } \\
\text { pressure, } \mathrm{mm} \mathrm{Hg}\end{array}$ & $142.6 \pm 18.9$ & $141.3 \pm 20.1$ \\
\hline $\begin{array}{l}\text { Diastolic blood } \\
\text { pressure, } \mathrm{mm} \mathrm{Hg}\end{array}$ & $78.6 \pm 10.4$ & $76.7 \pm 10.0$ \\
\hline Triglycerides, $\mathrm{mmol} / \mathrm{L}$ & $1.6(1.1-2.3)$ & $1.5(1.1-2.1)$ \\
\hline $\begin{array}{l}\text { Total cholesterol, } \\
\mathrm{mmol} / \mathrm{L}\end{array}$ & $4.28 \pm 1.12$ & $4.73 \pm 1.39$ \\
\hline $\mathrm{HDL}-\mathrm{C}, \mathrm{mmol} / \mathrm{L}$ & $1.14 \pm 0.32$ & $1.36 \pm 0.39$ \\
\hline LDL-c, mmol/L & $2.3 \pm 0.8$ & $2.6 \pm 1.0$ \\
\hline $\begin{array}{l}\text { Cholesterol ratio } \\
\text { (total:HDL) }\end{array}$ & $3.97 \pm 1.42$ & $3.69 \pm 1.27$ \\
\hline Weight, kg & $94.2 \pm 17.9$ & $85.5 \pm 18.8$ \\
\hline Height, cm & $177 \pm 7$ & $164 \pm 7$ \\
\hline $\begin{array}{l}\text { Body mass index, } \\
\mathrm{kg} / \mathrm{m}^{2}\end{array}$ & $30.0 \pm 5.2$ & $31.9 \pm 6.7$ \\
\hline $\begin{array}{l}\text { Waist circumference, } \\
\mathrm{cm}\end{array}$ & $108.4 \pm 13.6$ & $104.5 \pm 15.6$ \\
\hline $\mathrm{HbA}_{1 \mathrm{c}}, \mathrm{mmol} / \mathrm{mol}$ & $55.0 \pm 13.6$ & $55.4 \pm 14.2$ \\
\hline \multicolumn{3}{|l|}{ Medication use } \\
\hline \multicolumn{3}{|l|}{ Diabetes medication } \\
\hline None & $538(14)$ & $403(16)$ \\
\hline
\end{tabular}

Continued
Table 1 Continued

\begin{tabular}{lll}
\hline & $\begin{array}{l}\text { Men, } \\
\mathbf{n = 3 9 6 9 ( 6 0 \% )}\end{array}$ & $\begin{array}{l}\text { Women, } \\
\mathbf{n = 2 6 6 8 ~ ( 4 0 \% )}\end{array}$ \\
\hline \multicolumn{1}{|l}{ Oral only } & $1769(46)$ & $1097(42)$ \\
\hline $\begin{array}{l}\text { Insulin and oral } \\
\text { Insulin only }\end{array}$ & $1053(27)$ & $690(27)$ \\
$\begin{array}{l}\text { Lipid-modifying } \\
\text { medication }\end{array}$ & $2740(13)$ & $401(16)$ \\
$\begin{array}{l}\text { Antihypertensive } \\
\text { medication }\end{array}$ & $2688(69)$ & $1628(63)$ \\
$\begin{array}{l}\text { Antithrombotic } \\
\text { medication }\end{array}$ & $1689(44)$ & $802(31)$ \\
\hline
\end{tabular}

Data are presented as mean \pm SD or median (IQR) where appropriate for continuous variables and $\mathrm{n}(\%)$ for categorized variables.

Due to missing data not all variables add up to $n=2668$ for women and $n=3969$ for men.

*Low education includes no education, primary school not finished, primary education, and low vocational education. Moderate education includes intermediate vocational education, high secondary education, and high vocational education. High education includes high professional education and university education.

†Alcohol use was divided into three categories: none: no alcohol use; low: $\leq 7$ glasses per week for women and $\leq 14$ glasses per week for men; high: $>7$ glasses per week for women and $>14$ glasses per week for men.

CVD, cardiovascular disease; $\mathrm{HbA}_{10}$, hemoglobin $\mathrm{A}_{10}$; HDL-c, high-density lipoprotein cholesterol; LDL-c, lowdensity lipoprotein cholesterol.

\section{Pharmacological treatment and achievement of cardiometabolic risk factor targets}

Information on medication use for the treatment of hyperglycemia, dyslipidemia and hypertension was collected either by asking participants to bring their medication on the day of visit to the clinic or by use of pharmacy lists. Majority of individuals receiving treatment for hyperlipidemia (Anatomical Therapeutic Chemical Classification System C10) were treated with statins $(95 \%)$. Treatment with other types of lipid-modifying medication (ie, fibrates) was limited. Although newer antidiabetic medication became available during the study period (ie, Glucagon-like peptide-1 (GLP1) analogs and Sodiumglucose cotransporter-2 (SGLT2) inhibitors in 2009 and 2011, respectively), these were not yet prescribed to our study population. Pharmacological management of hyperglycemia, dyslipidemia and hypertension was each categorized into four groups, based on the individual's medication use, the levels of SBP, LDL-c and $\mathrm{HbA}_{1 \mathrm{c}}$ at target (ie, below or above cut-off), and the individual's estimated 10-year CVD risk (online supplemental table 1):

- No treatment and no treatment indication: not receiving glucose-lowering medication and $\mathrm{HbA}_{1 \mathrm{c}}$ $\leq 53 \mathrm{mmol} / \mathrm{mol}$; not receiving antihypertensive medication and $\mathrm{SBP} \leq 140 \mathrm{~mm} \mathrm{Hg}$, or SBP $>140 \mathrm{~mm} \mathrm{Hg}$ with 


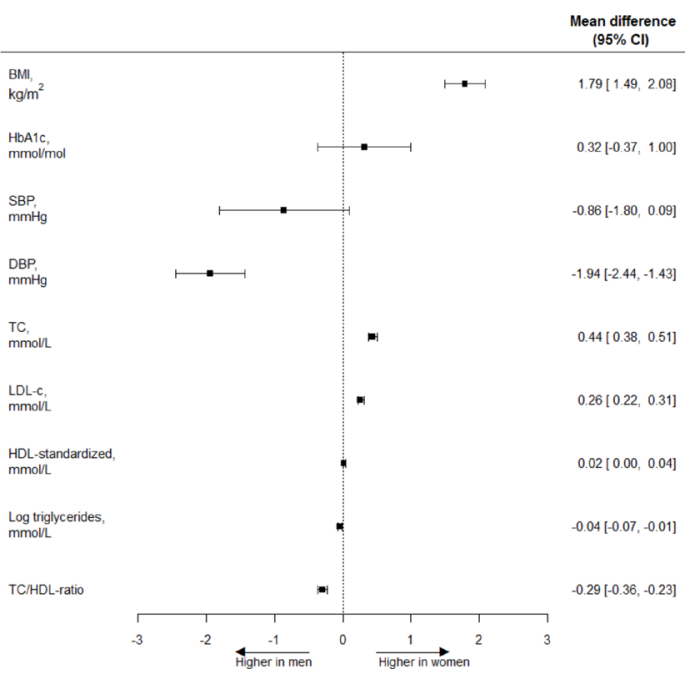

Figure 1 Age-adjusted women-to-men mean differences of cardiometabolic risk factor levels. A mean difference in BMI of $1.79 \mathrm{~kg} / \mathrm{m}^{2}$ means that the age-adjusted BMI in women is $1.79 \mathrm{~kg} / \mathrm{m}^{2}$ higher than in men. Back transformation of logtransformed triglycerides results in a geometric mean ratio of 0.91 (95\% Cl 0.85 to 0.98). Men: reference. BMI, body mass index; DBP, diastolic blood pressure; $\mathrm{HbA}_{1 \mathrm{c}}$, hemoglobin $A_{1 c}$; HDL-c, high-density lipoprotein cholesterol; LDL-c, lowdensity lipoprotein cholesterol; SBP, systolic blood pressure; TC, total cholesterol.

low or intermediate 10-year CVD risk; not receiving lipid-modifying medication and LDL-c $\leq 2.5 \mathrm{mmol} / \mathrm{L}$, or $>$ LDL-c $2.5 \mathrm{mmol} / \mathrm{L}$ with low or intermediate 10-year CVD risk.

- Optimal treatment: receiving glucose-lowering medication and $\mathrm{HbA}_{1 \mathrm{c}} \leq 53 \mathrm{mmol} / \mathrm{mol}$; receiving antihypertensive medication and $\mathrm{SBP} \leq 140 \mathrm{~mm} \mathrm{Hg}$; receiving lipid-modifying medication and LDL-c $\leq 2.5 \mathrm{mmol} / \mathrm{L}$.

- Suboptimal treatment: receiving glucose-lowering medication and $\mathrm{HbA}_{1 \mathrm{c}}>53 \mathrm{mmol} / \mathrm{mol}$; receiving antihypertensive medication and SBP >140 mm Hg; receiving lipid-modifying medication and LDL-c $>2.5 \mathrm{mmol} / \mathrm{L}$.

- No treatment despite a treatment indication: not receiving glucose-lowering medication despite $\mathrm{HbA}_{1 c}$ $>53 \mathrm{mmol} / \mathrm{mol}$; not receiving antihypertensive medication despite high CVD risk and SBP $>140 \mathrm{~mm} \mathrm{Hg}$; not receiving lipid-modifying medication despite high CVD risk and LDL-c $>2.5 \mathrm{mmol} / \mathrm{L}$.

The individual's 10-year risk of CVD was estimated by use of an adapted version of the SCORE risk model. Estimation of the 10-year CVD risk was based on sex, age (biological age +15 years to compensate for the increased CVD risk associated with T2D as recommended by the adapted version of the SCORE risk model according to Dutch guidelines), current smoking, SBP and TC:HDL ratio, and classified as low $(<10 \%)$, intermediate $(10 \%-$ $20 \%$ ) or high ( $>20 \%$ or prevalent CVD).$^{24}$

\section{Statistical analysis}

Population characteristics were described, by sex, as mean $\pm S D$ or median (IQR) where appropriate for continuous variables and $\mathrm{n}(\%)$ for categorized variables. Information on missing data can be found in online supplemental table 2.

Age and medication-adjusted linear regression analyses were performed to study sex differences in cardiometabolic risk factor levels. Linear regression analyses on $\mathrm{HbA}_{1 \mathrm{c}}$ were adjusted for glucose-lowering medication; analyses on the lipid spectrum were adjusted for lipidmodifying medication; and analyses on blood pressure were adjusted for antihypertensive medication.

Age-adjusted Poisson regression analyses ${ }^{25}$ with robust SEs were used to obtain RR with 95\% CI for sex differences in the treatment and achievement of cardiometabolic risk factor targets $\left(\mathrm{HbA}_{1 c}, \mathrm{SBP}\right.$, and LDL-c).

Given that the data used for this study were collected over a 6-year period and guidelines have changed over time, we additionally analyzed treatment based on risk factor levels irrespective of 10-year estimated CVD risk. Secondary interaction analyses on history of CVD (yes vs no), healthcare setting (primary care vs secondary care and tertiary care), age ( $<60$ years vs $\geq 60$ years), BMI $\left(<25 \mathrm{~kg} / \mathrm{m}^{2}\right.$ vs $\left.\geq 25 \mathrm{~kg} / \mathrm{m}^{2}\right)$, and educational level (low, middle, high) were performed. We decided to only adjust our analyses for age as other variables such as BMI are thought to be mediating factors, and our goal was to examine the independent effects of sex on treatment and achievement of risk factor targets.

Statistical analyses were performed using SPSS V.25.0 for Windows.

\section{RESULTS}

Data from 6637 individuals ( $40 \%$ women), with a mean age of 62 years and a median T2D duration of 9 years, were used. On average, men were more likely than women to smoke, drink alcohol, have a known history of CVD, have a high 10-year CVD risk, and to use lipidmodifying medication. Women had higher TC, LDL-C and HDL-c levels and higher BMI than men (table 1).

\section{Cardiometabolic risk factor levels}

Figure 1 shows the sex-specific cardiometabolic risk factor levels and age-adjusted associations between sex and cardiometabolic risk factor levels. Results are expressed as MD and 95\% CI. Compared with men, women had a higher BMI (MD $1.79 \mathrm{~kg} / \mathrm{m}^{2}(95 \%$ CI 1.49 to 2.08)) and similar levels of $\mathrm{HbA}_{1 \mathrm{c}}$ (MD $0.32 \mathrm{mmol} /$ mol (95\% CI -0.37 to 1.00$)$ ) and SBP (MD $-0.86 \mathrm{~mm} \mathrm{Hg}$ (95\% CI -1.80 to 0.09$)$ ). Furthermore, women had lower DBP (MD $-1.94 \mathrm{~mm} \mathrm{Hg}$ (95\% CI -2.44 to -1.43)), higher TC (MD $0.44 \mathrm{mmol} / \mathrm{L}(95 \%$ CI 0.38 to 0.51$)$ ), LDL-c (MD $0.26 \mathrm{mmol} / \mathrm{L}(95 \%$ CI 0.22 to 0.31$)$ ), and HDL-cstandardized (MD $0.02 \mathrm{mmol} / \mathrm{L}$ (95\% CI 0.00 to 0.04$)$ ), and lower TC:HDL ratio (MD -0.29 (95\% CI -0.36 to $-0.23)$ ) and triglycerides (geometric mean ratio 0.91 (95\% CI 0.85 to 0.98$)$ ) than men. Results did not change after additional adjustments for medication use (results not shown). 

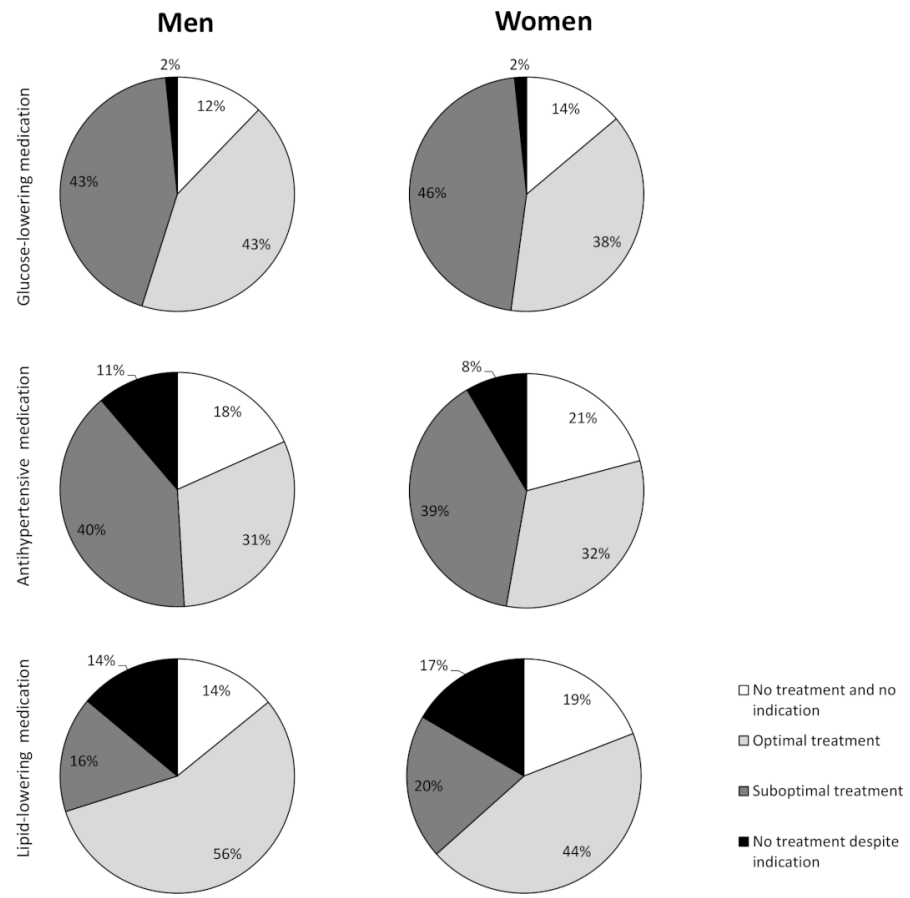

Figure 2 Pharmacological treatment and achievement of treatment targets of hyperglycemia (upper panel), hypertension (middle panel) and dyslipidemia (lower panel) in percentages for women and men. No treatment and no indication: no medication use and no indication for treatment (risk factor below cut-off or either low or medium 10-year CVD risk in case of SBP $>140 \mathrm{~mm} \mathrm{Hg}$ or LDL-C $>2.5 \mathrm{mmol} / \mathrm{L}$ ); optimal treatment: medication use and risk factor below cut-off; suboptimal treatment: medication use and risk factor above cut-off; no treatment despite indication: no medication use, but $\mathrm{HbA}_{1 \mathrm{c}}>53$ $\mathrm{mmol} / \mathrm{mol}$ or high 10-year CVD risk and SBP $>140 \mathrm{~mm} \mathrm{Hg}$ or LDL-C $>2.5 \mathrm{mmol} / \mathrm{L}$. CVD, cardiovascular disease; $\mathrm{HbA}_{1 \mathrm{c}}$, hemoglobin $\mathrm{A}_{10}$; LDL-c, low-density lipoprotein cholesterol; SBP, systolic blood pressure.

\section{Pharmacological treatment of cardiometabolic risk factors}

Figure 2 shows the pharmacological treatment of hyperglycemia, hypertension and dyslipidemia, among those without relevant missing data. Overall, $84 \%, 71 \%$ and $64 \%$ of women and $86 \%, 71 \%$ and $72 \%$ of men with known risk factor levels were treated with glucose-lowering, blood pressure-lowering or lipid-modifying medication, respectively.

Compared with men, women had a $16 \%$ higher probability of being treated with antihypertensive medication in the presence of high CVD risk and elevated SBP (RR 0.84 (95\% CI 0.73 to 0.98$)$ ), whereas no statistically

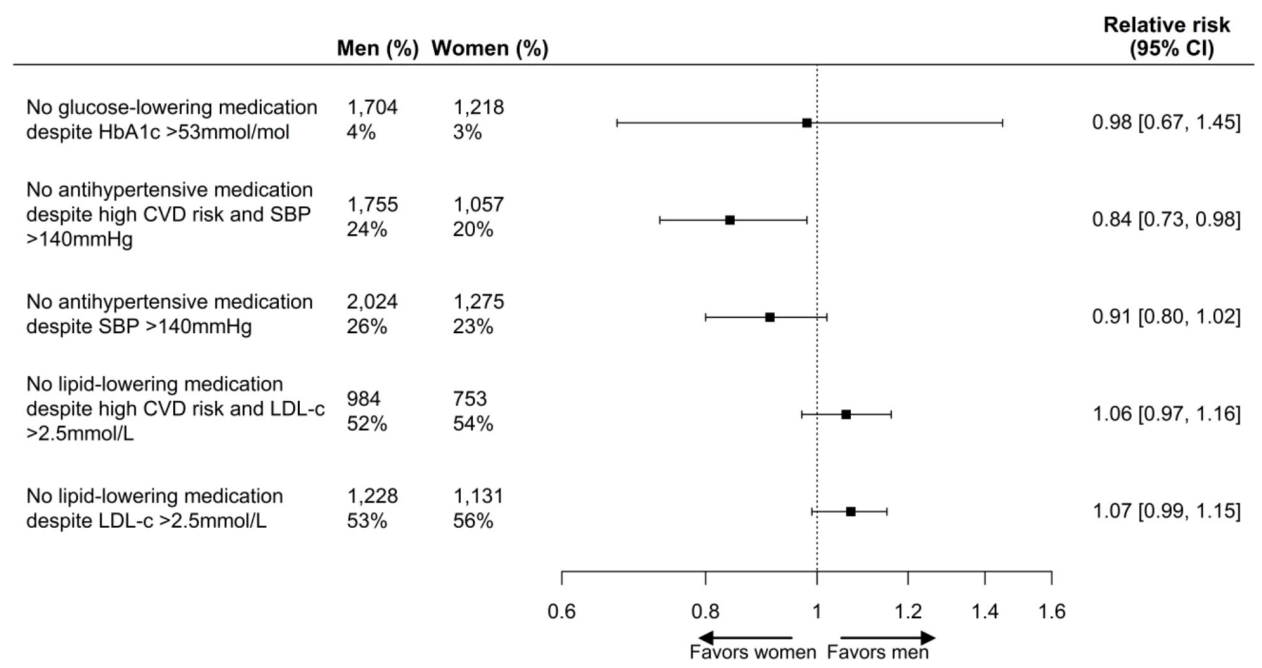

Figure 3 Age-adjusted women to men risk ratios with $95 \% \mathrm{Cl}$ for treatment of cardiometabolic risk factors according to risk factor levels and 10-year CVD risk score. Men and women refer to the total number of participants included in the analyses, and $\%$ refers to the number of participants not receiving glucose-lowering, antihypertensive or lipid-modifying medication. Men: reference. CVD, cardiovascular disease; $\mathrm{HbA}_{10}$; hemoglobin $\mathrm{A}_{1 \mathrm{c}}$; LDL-c, low-density lipoprotein cholesterol; SBP, systolic blood pressure. 
significant sex difference was found for being treated with antihypertensive medication in the presence of elevated SBP irrespective of high CVD risk (RR 0.91 ( $95 \%$ CI 0.80 to 1.02)). No sex differences were found for glucose-lowering medication in the presence of elevated $\mathrm{HbA}_{1 c}$ levels (RR 0.98 (95\% CI 0.67 to 1.45)), and lipidmodifying medication in the presence of elevated LDL-c levels and high CVD risk (RR 1.06 (95\% CI 0.97 to 1.16)) and irrespective of CVD risk (RR 1.07 (95\% CI 0.99 to 1.15)) (figure 3).

\section{Achievement of treatment targets}

Among those treated with glucose-lowering medication, blood pressure-lowering medication or lipid-modifying medication, $45 \%, 45 \%$ and $69 \%$ of women and $50 \%, 44 \%$ and $78 \%$ of men achieved targets of $\mathrm{HbA}_{1 \mathrm{c}}(\leq 53 \mathrm{mmol} /$ $\mathrm{mol})$, SBP $(\leq 140 \mathrm{~mm} \mathrm{Hg})$ or LDL-c $(\leq 2.5 \mathrm{~mol} / \mathrm{L})$, respectively. After adjustment for age, women were less likely to achieve risk factor targets of $\mathrm{HbA}_{1 \mathrm{c}}$ (RR 0.92 (95\% CI 0.87 to 0.98 ) ) and LDL-c (RR 0.89 (95\% CI 0.85 to 0.92$)$ ) than men, while no sex differences were found for control of SBP (RR 1.03 (95\% CI 0.96 to 1.10$)$ ).

\section{Subgroup and interaction analyses}

Results from the interaction analyses on history of CVD, healthcare setting (primary, secondary and tertiary care), age, BMI and educational level are summarized in online supplemental tables 3 and 4 .

For cardiometabolic risk factors, the interaction analyses by history of CVD, healthcare setting, age, BMI and educational level showed several significant interactions, but most differences were very small and unlikely to be clinically relevant (online supplemental table 3), with two exceptions. First, women with high educational level had lower SBP (MD $-4.34(95 \%$ CI -6.89 to -1.80$)$ ) than men, compared with lower educational levels $(\mathrm{p}=0.046)$. Second, women with low and middle educational levels had higher BMI compared with their male counterparts (MD $2.13(95 \%$ CI 1.58 to 2.67$)$ and MD 1.29 (95\% CI 0.80 to 1.78 ), respectively), while no statistically significant sex differences were found for high educational level (MD 0.49 (95\% CI -0.22 to 1.20$)$ ) $(\mathrm{p}<0.001)$.

Women with a history of CVD had a higher likelihood of not receiving lipid-modifying medication despite high CVD risk and elevated LDL-c than men (RR 1.26 (95\% CI 1.03 to 1.53 )), while no such sex difference was found for participants without CVD (RR 0.94 (95\% CI 0.83 to $1.05)$ ). Similar results for not receiving lipid-modifying medication in the presence of elevated LDL-c were found irrespective of high CVD risk. Women in primary care had a lower likelihood of not receiving antihypertensive medication despite high CVD risk and elevated SBP than men (RR 0.73 (95\% CI 0.61 to 0.88 )) in contrast to secondary or tertiary care (RR 1.12 (95\% CI 0.85 to 1.49$)$ ), and women in secondary or tertiary care had a higher likelihood of not receiving lipid-modifying medication despite high CVD risk and elevated LDL-c than men (RR 1.28 (95\% CI 1.08 to 1.53 )) (online supplemental table
4). Women with higher educational level had a higher likelihood of not receiving antihypertensive medication despite elevated SBP and high CVD risk than men (RR 1.27 (95\% CI 0.92 to 1.76$)$ ), while women with lower educational levels were more likely to receive antihypertensive medication (RR 0.74 (95\% CI 0.56 to 0.97 ). Similar results for not receiving antihypertensive or lipidmodifying medication were found, irrespective of high CVD risk.

With regard to achievement of treatment targets, women in secondary or tertiary care were less likely to attain $\mathrm{HbA}_{1 \mathrm{c}} \leq 53 \mathrm{mmol} / \mathrm{mol}$ than men when receiving glucose-lowering medication $(0.80 \quad(95 \%$ CI 0.71 to $0.90)$ ), while no such sex difference was found for participants in primary care $(0.96$ (95\% CI 0.89 to 1.03$))$ (online supplemental table 4). Moreover, women with higher educational levels were more likely to attain SBP $\leq 140 \mathrm{~mm} \mathrm{Hg}$ than men, when receiving antihypertensive medication (1.34 (95\% CI 1.13 to 1.58$)$ ).

\section{DISCUSSION}

Data from the Dutch Diabetes Pearl show that sex disparities in cardiometabolic risk factor levels, pharmacological treatment and achievement of cardiometabolic risk factor control exist, with three major findings. (1) Women, especially those with lower and middle educational levels, had a substantially higher BMI than men, while other cardiometabolic risk factors were highly comparable, although statistically significantly different for DBP and markers of dyslipidemia. (2) Women were more likely to receive antihypertensive medication in the presence of high CVD risk and increased SBP, while no differences were found for treatment with glucoselowering medication or lipid-modifying medication. (3) Proportions of men and women who did not achieve optimal treatments targets for glucose blood pressure and lipids, despite their treatment, were large, ranging from $22 \%$ to $56 \%$, and women were less likely to achieve treatment targets of $\mathrm{HbA}_{1 \mathrm{c}}$ and LDL-c, while receiving glucose-lowering and lipid-modifying medication.

\section{Cardiometabolic risk factor levels}

In women with T2D, BMI was $1.79 \mathrm{~kg} / \mathrm{m}^{2}$ higher than in men with T2D, which is in line with several previous studies conducted in various countries, including the Netherlands, Spain, Italy, and the UK, and more effective weight loss interventions are clearly needed..$^{26-29}$ It has been hypothesized that cardiometabolic risk factors need to deteriorate further in women than men before they develop overt T2D. ${ }^{2} 16183031$ As a consequence, women may be exposed to hazardous cardiometabolic risk factors for a longer period of time, which may increase their CVD risk. Sex differences in the metabolism and the storage of fat may be of particular interest, and several studies have shown that fat storage and distribution differ by sex, with women having a greater subcutaneous fat storage, while on average men have greater visceral and ectopic 
fat storages. ${ }^{15} 18$ Visceral and ectopic fat have been linked to insulin resistance. As a consequence, compared with men, women may need to gain more weight to store visceral and ectopic fat before developing insulin resistance and overt T2D. Thus, women may be exposed to hazardous cardiometabolic risk factors for an extended period of time before they are diagnosed with T2D and receive treatment. ${ }^{216183031}$

\section{Treatment of cardiometabolic risk factors}

Proportions of both men and women who did not receive antihypertensive or lipid-modifying treatment, despite high CVD risk and SBP $>140 \mathrm{~mm} \mathrm{Hg}$ or LDL-c $>2.5 \mathrm{mmol} / \mathrm{L}$, were substantial, ranging from $\sim 20 \%$ for hypertension to $\sim 50 \%$ for dyslipidemia, and women were more likely to receive antihypertensive treatment than men in the presence of high CVD risk and SBP $>140 \mathrm{~mm} \mathrm{Hg}$. These results are comparable with those of a Dutch primary care study, which found that $16 \%$ and $48 \%$ of those with a treatment indication did not receive prescriptions for antihypertensive and lipid-modifying medication, respectively. ${ }^{27}$ Based on our data we cannot assess the ground for this suboptimal CVD risk factor treatment. However, a focus on antihyperglycemic treatment rather than the treatment of hypertension or on individualized care with personalized treatment targets could play a role. Furthermore, patients may be reluctant to start certain medications, that is, statins, due to fear of side effects.

\section{Control of cardiometabolic risk factor levels}

Women with T2D receiving glucose-lowering or lipidmodifying medication were, respectively, $8 \%$ (RR 0.92 (95\% CI 0.87 to 0.98$)$ ) and $11 \%$ (RR 0.89 (95\% CI 0.85 to 0.92$)$ ) less likely to attain treatment targets than men, while no differences were found for antihypertensive treatment. Other studies on sex differences in achieving $\mathrm{HbA}_{1 \mathrm{c}}$ targets have reported mixed findings. In agreement with our findings, some other studies found that women were less likely to attain HbAlc targets, ${ }^{172832}$ while others did not. ${ }^{2627}$ A recent study including 53602 Dutch individuals with pharmacologically treated T2D found no clear sex differences in goal attainment of $\mathrm{HbA}_{1 \mathrm{c}}$ and SBP, while women were less likely to attain LDL-c control compared with men. ${ }^{33}$ A higher BMI of women with T2D, presumably with higher insulin resistance, could explain the lower attainment of $\mathrm{HbA}_{1 \mathrm{c}}$ targets in our study. The finding of worse LDL-c control among women with T2D is consistent with previous studies which showed an OR of up to $44 \%$. $^{17} 26-2832$ Possible explanations include a differential biological response to lipid-modifying medication, or sex differences in dosage, type of medication, medication tolerance or adherence. In the general population, several studies have shown the adherence to blood pressure-lowering and lipid-lowering medication to be lower in women than in men. ${ }^{34-36}$ To our knowledge, such studies have not yet been conducted in individuals with T2D. Furthermore, a recently published systematic review studying the participation of women in 740 cardiovascular clinical trials with 862652 participants showed that, although this has improved over the last decade, men still predominate majority of cardiovascular clinical trials. ${ }^{37}$ Reporting sex-specific results from clinical trials is important to obtain more insight into potential sex differences of treatment benefit and medication tolerance. Therefore, novel approaches to the recruitment and enrollment process and novel trial designs are needed to ensure that sex-specific results may be meaningfully obtained and applied to clinical practice. ${ }^{37}$

Another possible explanation may be found in differences of cardiometabolic risk factor levels at treatment initiation. As discussed earlier, it has been hypothesized that cardiometabolic risk factors need to deteriorate further in women than men before they are diagnosed with overt T2D. Therefore, it may take more aggressive treatment strategies to lower cardiometabolic risk factor levels in women compared with men.

\section{Sex-specific risk factors}

Certain factors that may impact cardiovascular risk are unique to women, including higher levels of female hormones, age of menarche, age of menopause and use of oral contraceptive and hormonal therapy. Studying the impact of sex hormones on the development of cardiovascular complications is challenging, especially given the cyclic fluctuations in hormone levels among women. However, we did not find evidence in the magnitude of sex differences among younger and older (as proxy for menopausal status) participants in subgroup analyses. Previous studies have found several female reproductive factors, including childbearing history, age at menarche, and age at menopause, to be associated with adiposity, ${ }^{38} 39$ thereby suggesting that female reproductive factors may be involved in the development of T2D and cardiovascular complications. ${ }^{13}$ Future studies are needed to further investigate the direct impact of sex hormones on the onset of CVD.

\section{Clinical implications}

The development of diabetes and cardiovascular complications is a process of decades. As mentioned before, it has been hypothesized that women may be exposed to a hazardous cardiovascular environment for a longer period than men before the onset of diabetes. This hypothesis is supported by a study showing that, on average, men have pre-diabetes for 8 years and women for 10 years. ${ }^{40}$ This time window may offer clinicians the opportunity to identify those at increased risk for diabetes and subsequently offer the opportunity for timely intervention. ${ }^{31}$

As cardiovascular risk factor levels seem to deteriorate more strongly in women than in men, before the onset of diabetes, ${ }^{16}$ it is of great importance to conduct a thorough cardiovascular risk assessment in women at risk of diabetes and those with overt diabetes, while not neglecting men. ${ }^{31}$ Moreover, increasing awareness among physicians about the stronger deterioration of risk factors in women is 
recommended to prevent women with diabetes from being treated less aggressively than men. ${ }^{31}$

Finally, this study showed that both men and women with T2D had high BMI levels, with women having a considerably higher BMI than men. These results are in accordance with previous literature, and effective weight loss strategies seem urgently needed with better facilitation of lifestyle changes. ${ }^{31}$

\section{Strengths and limitations}

This large cohort included individuals with T2D receiving primary, secondary, and tertiary care in one of eight medical centers across the Netherlands covering different geographical areas, and thereby provides a well-phenotyped cohort of Dutch individuals with T2D. Nevertheless, our study also has limitations.

Data were collected over a 6-year period (2009-2015). ${ }^{22}$ Given the rapid change of guidelines for the treatment of diabetes, some of our results may be less generalizable to current clinical practice. Nevertheless, the main aim of our study was to investigate sex differences in the management of diabetes. Since most of the evidencebased guidelines provide similar recommendations for both sexes and no sex-specific recommendations were published over time, valid conclusions about sex differences can be drawn from the available data that were used for this study. Guidelines on diabetes care increasingly focus on individualized care. Therefore, the more general treatment targets used in this study may have limited the generalizability of the findings to clinical practice. Moreover, a strict definition of CVD risk was used in this study without taking risk-enhancing factors, that is, family history of CVD, into account. ${ }^{24}$ As a result, the proportion of individuals with a treatment indication at baseline might be underestimated. Although we do not expect substantial differences in risk-enhancing factors between women and men, the proportions of women and men with an intermediate CVD risk did differ ( $14 \%$ vs $5 \%$, respectively), which might have led to more misclassified women than men. As a result, sex differences might be underestimated or overestimated.

Furthermore, individuals were indicated to receive lipid-modifying medication in case of a high 10-year CVD risk combined with LDL-c level $>2.5 \mathrm{mmol} / \mathrm{L}$. This cut-off value was adopted from the Dutch guideline cardiovascular risk management, which is used in primary care. ${ }^{24}$ In secondary and tertiary care, physicians often use a cutoff value of $>1.8 \mathrm{mmol} / \mathrm{L}$ when patients have a history of CVD, which means that we have been less strict than in clinical practice.

Finally, in this study we examined sex differences in the management of diabetes using a cross-sectional design. However, the management of diabetes and the prevention and delay of diabetes complications are an ongoing dynamic process. For example, optimal treatment was defined as achievement of prespecified treatment targets according to current guidelines, while in reality the absolute drop in cardiovascular levels from the start of treatment may be more important. Also, medication use and risk factor levels are obtained at the same time, while setting the right treatment regimen takes time. Unfortunately, due to the cross-sectional design, we do not have the information to take the dynamics of this process into account. This requires further investigation, ideally in studies with repeated risk factor measurements and longitudinal follow-up of pharmacological interventions.

\section{CONCLUSION}

In summary, in this population of Dutch individuals with T2D from primary, secondary and tertiary care, women had a considerably higher BMI than men and a greater difficulty in attaining $\mathrm{HbA}_{1 \mathrm{c}}$ and LDL-c treatment targets, while men were less likely to receive antihypertensive medication despite high CVD risk and elevated SBP. Effective weight loss strategies seem urgently needed.

\section{Author affiliations}

${ }^{1}$ Julius Center for Health Sciences and Primary Care, University Medical Center Utrecht, Utrecht University, Utrecht, The Netherlands

${ }^{2}$ Department of Internal Medicine, School for Cardiovascular Diseases CARIM, Maastricht University Medical Centre+, Maastricht, The Netherlands

${ }^{3}$ Department of Internal Medicine, Erasmus Medical Center, Rotterdam, The Netherlands

${ }^{4}$ Department of Epidemiology and Biostatistics, Amsterdam UMC - VUMC location, Amsterdam, The Netherlands

${ }^{5}$ Department of General Practice and Elderly Care, Amsterdam Public Health Research Institute, Amsterdam UMC - VUMC location, Amsterdam, The Netherlands ${ }^{6}$ Department of Internal Medicine, Amsterdam UMC, University of Amsterdam, Amsterdam, The Netherlands

${ }^{7}$ Department of Internal Medicine, Radboud University Medical Center, Nijmegen, The Netherlands

${ }^{8}$ Department of Internal Medicine, Division of Endocrinology, Leiden University Medical Center, Leiden, The Netherlands

${ }^{9}$ Department of Internal Medicine, Universty Medical Center Utrecht, Utrecht University, Utrecht, The Netherlands

${ }^{10}$ Department of Internal Medicine, University of Groningen, University Medical Center Groningen, Groningen, The Netherlands

${ }^{11}$ The George Institute for Global Health, Imperial College London, London, UK

${ }^{12}$ The George Institute for Global Health, University of New South Wales, Sydney, New South Wales, Australia

Acknowledgements We would like to thank all the participants and contributors to the Dutch Diabetes Pearl from the Parelsnoer Initiative in the Netherlands.

Collaborators L 't Hart; N C Schaper; 0 M Dekkers; B Silvius; M M van der Klauw.

Contributors MJO and MTS conceived and designed the study. MJO and MdJ analyzed the data and wrote the manuscript. SJSS, BO, FR, EJGS, PJME, SES, JHDV, CJT, MS, HWdV, EJA, CDAS, IJ, BHRW, SAEP, and MTS critically revised the manuscript for intellectual content. All authors read and approved the final manuscript. MTS is the guarantor of this work and as such had full access to all the data in the study and takes responsibility for the integrity of the data and the accuracy of the data analysis.

Funding The work described in this study was carried out in the context of the Parelsnoer Initiative (PSI). PSI is part of and is funded by the Dutch Federation of University Medical Centres and from 2007 to 2011 received initial funding from the Dutch Government. MdJ is funded by a grant from the Netherlands Organisation for Health Research and Development (ZonMw), Gender and Health Programme (80-84900-98-100). SAEP is supported by a UK Medical Research Council Skills Development Fellowship (MR/P014550/1). The funders had no role in the design and conduct of the study; analyses and interpretation of data; or preparation, review or approval of the manuscript.

Competing interests None declared.

Patient consent for publication Not required. 
Ethics approval The Diabetes Pearl was approved by the ethics committee of the VU University Medical Center (7 September 2009, ref: NL27783.029.09). All participants signed informed consent.

\section{Provenance and peer review Not commissioned; externally peer reviewed.}

Data availability statement No data are available. Proposals for collaborative research can be submitted to FR (f.rutters@vumc.nl).

Open access This is an open access article distributed in accordance with the Creative Commons Attribution 4.0 Unported (CC BY 4.0) license, which permits others to copy, redistribute, remix, transform and build upon this work for any purpose, provided the original work is properly cited, a link to the licence is given, and indication of whether changes were made. See: https://creativecommons.org/ licenses/by/4.0\%.

\section{ORCID iDs}

Marit de Jong http://orcid.org/0000-0001-9260-4458

Marielle Schroijen http://orcid.org/0000-0001-8865-0224

Sanne A E Peters http://orcid.org/0000-0003-0346-5412

Miranda T Schram http://orcid.org/0000-0001-8113-7604

\section{REFERENCES}

1 Tramunt B, Smati S, Grandgeorge N, et al. Sex differences in metabolic regulation and diabetes susceptibility. Diabetologia 2020;63:453-61.

2 Recarti C, Sep SJS, Stehouwer CDA, et al. Excess cardiovascular risk in diabetic women: a case for intensive treatment. Curr Hypertens Rep 2015;17:554.

3 Booth GL, Kapral MK, Fung K, et al. Relation between age and cardiovascular disease in men and women with diabetes compared with non-diabetic people: a population-based retrospective cohort study. Lancet 2006;368:29-36.

4 Kappert K, Böhm M, Schmieder R, et al. Impact of sex on cardiovascular outcome in patients at high cardiovascular risk: analysis of the telmisartan randomized assessment study in ACEIntolerant subjects with cardiovascular disease (TRANSCEND) and the ongoing telmisartan alone and in combination with ramipril global end point trial (ONTARGET). Circulation 2012;126:934-41.

5 Anand SS, Islam S, Rosengren A, et al. Risk factors for myocardial infarction in women and men: insights from the INTERHEART study. Eur Heart J 2008;29:932-40.

6 Kanaya AM, Grady D, Barrett-Connor E. Explaining the sex difference in coronary heart disease mortality among patients with type 2 diabetes mellitus: a meta-analysis. Arch Intern Med 2002;162:1737-45 http://www.ncbi.nlm.nih.gov/pubmed/12153377

7 Lee WL, Cheung AM, Cape D, et al. Impact of diabetes on coronary artery disease in women and men: a meta-analysis of prospective studies. Diabetes Care 2000;23:962-8 http://www.ncbi.nlm.nih.gov/ pubmed/10895847

8 Peters SAE, Huxley RR, Woodward M. Diabetes as risk factor for incident coronary heart disease in women compared with men: a systematic review and meta-analysis of 64 cohorts including 858,507 individuals and 28,203 coronary events. Diabetologia 2014;57:1542-51.

9 Peters SAE, Huxley RR, Woodward M. Diabetes as a risk factor for stroke in women compared with men: a systematic review and metaanalysis of 64 cohorts, including 775385 individuals and 12539 strokes. The Lancet 2014;383:1973-80.

10 Regensteiner JG, Golden S, Huebschmann AG, et al. Sex differences in the cardiovascular consequences of diabetes mellitus: a scientific statement from the American heart association. Circulation 2015;132:2424-47.

11 Golden SH, Dobs AS, Vaidya D, et al. Endogenous sex hormones and glucose tolerance status in postmenopausal women. J Clin Endocrinol Metab 2007;92:1289-95.

12 Oh J-Y, Barrett-Connor E, Wedick NM, et al. Endogenous sex hormones and the development of type 2 diabetes in older men and women: the Rancho Bernardo study. Diabetes Care 2002;25:55-60 http://www.ncbi.nlm.nih.gov/pubmed/11772901

13 Peters SAE, Woodward M. Sex differences in the burden and complications of diabetes. Curr Diab Rep 2018;18:33.

14 Peters SA, Woodward M. Women's reproductive factors and incident cardiovascular disease in the UK Biobank. Heart 2018;104:1069-75.

15 Woodward M, Peters SAE, Huxley RR. Diabetes and the female disadvantage. Womens Health 2015;11:833-9.

16 de Ritter R, Sep SJS, van der Kallen CJH, et al. Adverse differences in cardiometabolic risk factor levels between individuals with prediabetes and normal glucose metabolism are more pronounced in women than in men: the Maastricht study. BMJ Open Diabetes Res Care 2019;7:e000787.

17 Gouni-Berthold I, Berthold HK, Mantzoros CS, et al. Sex disparities in the treatment and control of cardiovascular risk factors in type 2 diabetes. Diabetes Care 2008;31:1389-91.

18 de Ritter R, de Jong M, Vos RC, et al. Sex differences in the risk of vascular disease associated with diabetes. Biol Sex Differ 2020;11:1.

19 Penno G, Solini A, Bonora E, et al. Gender differences in cardiovascular disease risk factors, treatments and complications in patients with type 2 diabetes: the RIACE Italian multicentre study. $J$ Intern Med 2013;274:176-91.

20 Kautzky-Willer A, Kamyar MR, Gerhat D, et al. Sex-Specific differences in metabolic control, cardiovascular risk, and interventions in patients with type 2 diabetes mellitus. Gend Med 2010;7:571-83.

21 Franzini L, Ardigò D, Cavalot F, et al. Women show worse control of type 2 diabetes and cardiovascular disease risk factors than men: results from the MIND.IT Study Group of the Italian Society of Diabetology. Nutr Metab Cardiovasc Dis 2013;23:235-41.

22 van't Riet E, Schram MT, Abbink EJ, et al. The diabetes pearl: diabetes biobanking in The Netherlands. BMC Public Health 2012;12:949

23 Volksgezondheidenzorg. Prevalentie diabetes in huisartsenpraktijk naar leeftijd en geslacht. Available: https://www.volksgezondheide nzorg.info/onderwerp/diabetes-mellitus/cijfers-context/huidigesituatie\#node-prevalentie-diabetes-huisartsenpraktijk-naar-leeftijden-geslacht [Accessed 4 Jun 2020]

24 NHG. Cardiovasculair risicomanagement. Available: https:// www.nhg.org/standaarden/samenvatting/cardiovasculairrisicomanagement [Accessed 7 May 2019].

$25 \mathrm{Knol}$ MJ, Le Cessie S, Algra A, et al. Overestimation of risk ratios by odds ratios in trials and cohort studies: alternatives to logistic regression. CMAJ 2012;184:895-9.

26 Franch-Nadal J, Mata-Cases M, Vinagre I, et al. Differences in the cardiometabolic control in type 2 diabetes according to gender and the presence of cardiovascular disease: results from the eControl study. Int J Endocrinol 2014;2014:1-11.

27 de Jong M, Vos RC, de Ritter R, et al. Sex differences in cardiovascular risk management for people with diabetes in primary care: a cross-sectional study. BJGP Open 2019;3:bjgpopen19X101645.

28 Rossi MC, Cristofaro MR, Gentile S, et al. Sex disparities in the quality of diabetes care: biological and cultural factors may play a different role for different outcomes: a cross-sectional observational study from the AMD Annals initiative. Diabetes Care 2013;36:3162-8.

29 Logue J, Walker JJ, Colhoun HM, et al. Do men develop type 2 diabetes at lower body mass indices than women? Diabetologia 2011:54:3003-6.

30 Peters SAE, Huxley RR, Woodward M. Diabetes as a risk factor for stroke in women compared with men: a systematic review and metaanalysis of 64 cohorts, including 775,385 individuals and 12,539 strokes. Lancet 2014;383:1973-80

31 Peters SAE, Huxley RR, Sattar N, et al. Sex differences in the excess risk of cardiovascular diseases associated with type 2 diabetes: potential explanations and clinical implications. Curr Cardiovasc Risk Rep 2015:9:36.

32 Wexler DJ, Grant RW, Meigs JB, et al. Sex disparities in treatment of cardiac risk factors in patients with type 2 diabetes. Diabetes Care 2005:28:514-20.

33 Heintjes EM, Houben E, Beekman-Hendriks WL, et al. Trends in mortality, cardiovascular complications, and risk factors in type 2 diabetes. Neth J Med 2019;77:317-29 http://www.ncbi.nlm.nih.gov/ pubmed/31814586

34 Gupta P, Patel P, Strauch B, et al. Risk factors for nonadherence to antihypertensive treatment. Hypertension 2017;69:1113-20.

35 Goldstein KM, Zullig LL, Bastian LA, et al. Statin adherence: does gender matter? Curr Atheroscler Rep 2016;18:63.

36 Lewey J, Shrank WH, Bowry ADK, et al. Gender and racial disparities in adherence to statin therapy: a meta-analysis. Am Heart J 2013;165:665-78.

37 Jin X, Chandramouli C, Allocco B, et al. Women's participation in cardiovascular clinical trials from 2010 to 2017. Circulation 2020;141:540-8

38 SA P, RR H MW. Women's Reproductive Health Factors and Body Adiposity: Findings From the UK Biobank. Int J Obes 2016;40.

39 Yang L, Li L, Millwood IY, et al. Adiposity in relation to age at menarche and other reproductive factors among 300000 Chinese women: findings from China Kadoorie Biobank study. Int J Epidemiol 2017;46:502-12.

40 Bertram MY, Vos T. Quantifying the duration of pre-diabetes. Aust N Z J Public Health 2010;34:311-4. 